\title{
The effect of cataract surgery on ocular dominance
}

\section{Roy Schwartz \\ Yossi Yatziv}

Ophthalmology Department, Tel Aviv Sourasky Medical Center and The Sackler Faculty of Medicine, Tel Aviv University, Tel Aviv, Israel
Correspondence: Roy Schwartz Ophthalmology Department, Tel Aviv Sourasky Medical Center and The Sackler Faculty of Medicine, Tel Aviv University, 6 Weizmann Street, Tel Aviv 64239, Israel Tel +972 36973408 Email royschwartz@gmail.com
This article was published in the following Dove Press journal:

Clinical Ophthalmology

14 December 2015

Number of times this article has been viewed

Purpose: The aim of this study is to assess whether eye dominance may change after cataract surgery.

Methods: This is a prospective case series. Cataract surgery candidates were examined prior to surgery for best-corrected visual acuity, eye dominance, and handedness. Patients with ocular conditions that may affect visual acuity were excluded from the study. A month following surgery, best-corrected visual acuity and eye dominance examinations were repeated.

Results: The study included 33 patients with a mean age of $70.5 \pm 9.4$ years. Eighteen patients $(54.5 \%)$ had right eye dominance. Following surgery, seven patients $(21.2 \%)$ had a change in eye dominance. The change in dominance was linked to improved visual acuity in the operated eye and to a younger age, although with no statistical significance.

Conclusion: This is the first study reported in the literature to show that ocular dominance is a plastic characteristic following cataract surgeries. The results may change the importance given to eye dominance measurement prior to surgeries that rely on this examination, such as monovision surgeries.

Keywords: monovision, cataract, dominance, refractive, surgery

\section{Introduction}

Ocular dominance is the tendency to prefer visual input from one eye to the other. ${ }^{1}$ It refers to the eye used preferentially in different forms of visual alignment and for carrying out monocular activities, such as sighting through a telescope, microscope, and keyhole or when using a gun. ${ }^{2}$

The implications of ocular dominance in the field of ophthalmology are refractive and cataract surgeries in which the patient is aimed for monovision. Monovision is a means of presbyopic correction where one eye is corrected for distance vision and the other for near vision. ${ }^{3}$ The success of monovision depends on interocular blur suppression, where the blurred image from one eye does not interfere with the image from the in-focus eye. In clinical practice, the dominant eye is commonly corrected for distance. It is based on the assumption that it is easier to suppress blur in the nondominant eye than in the dominant eye.

Diagnostic tests that aim to determine ocular dominance can be divided into two groups. The first group, motor tests, forces subjects to use monocular viewing (eg, by looking at an object through a small aperture). Confronted with these challenges, people tend to favor one eye over the other. Dominance tested in this fashion is termed sighting dominance. The second group, sensory dominance or ocular prevalence, measures a balance of sensory input between the eyes. ${ }^{4}$

Although reliance on dominance in the practice of ocular surgeries has significant implications, the stability of a person's dominance was never tested. The aim of this study was to examine whether ocular dominance, as tested by a sighting dominance technique, is static or may change after cataract surgeries. 


\section{Methods}

Cataract surgery candidates arriving at the cataract presurgery clinic were included in the study. Patients were included if they experienced visual deterioration that was related to the development of cataract. Selection criteria of the eye for cataract surgery was based on worse visual acuity, quality of vision as reported by the patient, cataract density, and patient preference, as is customary in the clinic.

Exclusion criteria included 1) ocular conditions other than cataract that may affect visual acuity, including retinal diseases and glaucoma, and 2) amblyopia in either eye.

A few weeks prior to surgery, patients were examined for best-corrected visual acuity, eye dominance, and handedness.

Best-corrected visual acuity was determined by an optometrist. Ocular dominance was determined using the hole-in-the-card dominance test (Dolman's test), ${ }^{5}$ a sighting dominance technique, in which patients were given a piece of paper with a central circular hole $3 \mathrm{~cm}$ in diameter. The patients were asked to hold the paper with both hands and view a target $6 \mathrm{~m}$ away through the hole, with both eyes open. Each eye was then occluded in turn. When the dominant eye was covered, the target could not be seen through the hole, while with the nondominant eye being covered, the dominant eye continued to fix the target through the aperture. This method is one of the most widely used dominance tests and was shown to be a suitable method when determining the dominant eye for monovision practices. ${ }^{4}$ The patients were asked to state their hand laterality.

Cataract surgery was performed using topical anesthesia. A monofocal aspheric, hydrophilic, acrylic intraocular lens (Bi Flex, Medicontur) was implanted using an injector following ultrasonic emulsification. Subjects were aimed for emmetropia using an appropriate intraocular lens as measured by the SRK/T formula. None of the subjects were aimed for monovision in this study.

A month following cataract surgery, best-corrected visual acuity and eye dominance were examined again using the methods described earlier.

Data were recorded in Microsoft Excel and analyzed using SPSS Version 21 (IBM Corporation, Armonk, NY, USA). Continuous variables were analyzed by a two-sided $t$-test. The Fisher's exact test or Pearson's chi-square test was used to explore categorical variables.

The study adhered to the tenets of the Declaration of Helsinki and was approved by the medical center institutional review board committee. Written informed consent was obtained from all patients.

\section{Results}

Thirty-three patients undergoing cataract surgeries were included in the study. The mean age was $70.5( \pm 9.4)$ years. Sixteen (48.5\%) were men and 17 (51.5\%) were women.

Baseline data and demographic characteristics are presented in Table 1.

No intraoperative complications occurred in any of the surgeries (eg, posterior capsular tear and vitreous loss). One patient suffered from postoperative corneal edema that lasted through the month until her follow-up visit.

No correlation was seen between eye and hand dominance. Right eye (RE) dominance was found in $55.2 \%$ of patients with right-hand dominance and in $50 \%$ of patients with lefthand dominance $(P=1.0)$.

Of the 33 patients included, 31 underwent cataract surgery in one eye by the time of repeated dominance measurement. Two arrived for the repeated measurement after undergoing an additional cataract surgery in the second eye. Following surgery, seven patients $(21.2 \%)$ had a change in ocular dominance. Six of them had cataract surgery in one eye, and the seventh patient was examined following surgery for both eyes. The change was in all cases from nondominance to dominance.

Table 2 elaborates visual acuity and dominance parameters for each patient before and following surgery. We assessed the relationship between visual acuity at baseline and eye dominance and the relationship between dominance change and visual acuity improvement. We found a positive correlation between the eye with the better visual acuity at baseline and the dominant eye (Figure 1). In 25 patients, one eye had better visual acuity than the other at baseline. Of those, in 20 patients (80\%), the eye with the better visual acuity was also the dominant eye. In eight eyes, there was no difference in visual acuity between the eyes at baseline.

Table I Demographic data and baseline characteristics

\begin{tabular}{ll}
\hline Age, years & $70.5( \pm 9.4)$ \\
Sex, $\mathrm{n}(\%)$ & $16(48.5)$ \\
$\quad$ Men & $17(51.5)$ \\
$\quad$ Women & \\
Dominant hand, $\mathrm{n}(\%)$ & $29(87.9)$ \\
$\quad$ Right & $4(12.1)$ \\
$\quad$ Left & \\
Dominant eye, $\mathrm{n}(\%)$ & $18(54.5)$ \\
$\quad$ Right & $15(45.5)$ \\
$\quad$ Left & 0.68 \\
Mean BCVA before surgery, operated eye (LogMAR) & 0.12 \\
Mean BCVA after surgery, operated eye (LogMAR) &
\end{tabular}

Abbreviations: BCVA, best-corrected visual acuity; LogMAR, logarithm of the minimum angle of resolution. 
Table 2 Change in visual acuity and dominance after cataract surgery

\begin{tabular}{|c|c|c|c|c|c|}
\hline Patient & $\begin{array}{l}\text { Operated eye } \\
\text { (RE/LE/BE) }\end{array}$ & $\begin{array}{l}\text { RE BCVA prior to } \\
\text { surgery (LogMAR) }\end{array}$ & $\begin{array}{l}\text { LE BCVA prior to } \\
\text { surgery (LogMAR) }\end{array}$ & $\begin{array}{l}\text { RE BCVA postsurgery } \\
\text { (LogMAR) }\end{array}$ & $\begin{array}{l}\text { LE BCVA postsurgery } \\
\text { (LogMAR) }\end{array}$ \\
\hline 1 & RE & 1.48 & $0.52^{\mathrm{a}, \mathrm{b}}$ & $0.18^{\mathrm{a}}$ & $0.52^{b}$ \\
\hline 2 & LE & $0.12^{\mathrm{a}, \mathrm{b}}$ & 1.3 & $0.12^{\mathrm{b}}$ & $0^{a}$ \\
\hline 3 & LE & $0.07^{\mathrm{a}, \mathrm{b}}$ & 0.4 & $0.07^{b}$ & $0^{a}$ \\
\hline $4^{c}$ & LE & $0.88^{\mathrm{b}}$ & $0.7^{\mathrm{a}}$ & $0.88^{\mathrm{b}}$ & $0.7^{\mathrm{a}}$ \\
\hline 5 & RE & $0.4^{\mathrm{a}, \mathrm{b}}$ & $0.4^{\mathrm{a}}$ & $0^{a, b}$ & 0.4 \\
\hline 6 & LE & $0.3^{a, b}$ & $0.3^{\mathrm{a}}$ & $0.3^{b}$ & $0^{a}$ \\
\hline 7 & LE & $0.3^{b}$ & $0.18^{\mathrm{a}}$ & $0.3^{\mathrm{b}}$ & $0.12^{\mathrm{a}}$ \\
\hline 8 & LE & $0.3^{a}$ & $0.3^{\mathrm{a}, \mathrm{b}}$ & 0.3 & $0^{a, b}$ \\
\hline $9^{d}$ & RE & $0.4^{\mathrm{a}}$ & $0.4^{\mathrm{a}, \mathrm{b}}$ & $0^{a, b}$ & 0.4 \\
\hline $10^{\mathrm{d}}$ & LE & $0.52^{\mathrm{a}, \mathrm{b}}$ & $0.52^{\mathrm{a}}$ & 0.52 & $0.18^{\mathrm{a}, \mathrm{b}}$ \\
\hline $1 I^{d}$ & RE & 0.82 & $0.22^{\mathrm{a}, \mathrm{b}}$ & $0^{a, b}$ & 0.22 \\
\hline 12 & LE & $0.3^{\mathrm{a}, \mathrm{b}}$ & 1.38 & $0.3^{b}$ & $0.12^{\mathrm{a}}$ \\
\hline $13^{d}$ & $\mathrm{RE}$ & $0.82^{\mathrm{a}}$ & $0.82^{\mathrm{a}, \mathrm{b}}$ & $0.18^{\mathrm{a}, \mathrm{b}}$ & 1 \\
\hline 14 & RE & $0.3^{\mathrm{a}}$ & $0.3^{\mathrm{a}, \mathrm{b}}$ & $0.18^{\mathrm{a}}$ & $0.3^{b}$ \\
\hline $15^{d}$ & RE & 3 & $0.18^{\mathrm{a}, \mathrm{b}}$ & $0.12^{\mathrm{a}, \mathrm{b}}$ & 0.18 \\
\hline 16 & LE & $0.3^{a, b}$ & 0.52 & $0.3^{b}$ & $0.12^{\mathrm{a}}$ \\
\hline $17^{d}$ & $\mathrm{BE}$ & 1.3 & $0.52^{\mathrm{a}, \mathrm{b}}$ & $0^{a, b}$ & $0^{\mathrm{a}}$ \\
\hline $18^{d}$ & LE & $0.18^{a, b}$ & 0.48 & $0.18^{\mathrm{a}}$ & $0.18^{\mathrm{a}, \mathrm{b}}$ \\
\hline 19 & RE & 0.4 & $0.3^{\mathrm{a}, \mathrm{b}}$ & $0^{\mathrm{a}}$ & $0.3^{\mathrm{b}}$ \\
\hline 20 & LE & $0.3^{\mathrm{a}}$ & $0.52^{\mathrm{b}}$ & 0.3 & $0.12^{\mathrm{a}, \mathrm{b}}$ \\
\hline 21 & $\mathrm{BE}$ & $0.7^{b}$ & $0.4^{\mathrm{a}}$ & $0.3^{\mathrm{a}, \mathrm{b}}$ & $0.3^{\mathrm{a}}$ \\
\hline 22 & RE & 0.3 & $0.18^{\mathrm{a}, \mathrm{b}}$ & $0.07^{\mathrm{a}}$ & $0.18^{b}$ \\
\hline 23 & LE & $0.3^{\mathrm{a}, \mathrm{b}}$ & 0.4 & $0.3^{b}$ & $0.12^{\mathrm{a}}$ \\
\hline 24 & RE & 0.7 & $0.4^{\mathrm{a}, \mathrm{b}}$ & $0.18^{\mathrm{a}}$ & $0.4^{b}$ \\
\hline 25 & RE & $0.7^{\mathrm{a}, \mathrm{b}}$ & 0.82 & $0.3^{\mathrm{a}, \mathrm{b}}$ & 0.82 \\
\hline 26 & RE & $0.3^{b}$ & $0.18^{\mathrm{a}}$ & $0^{a, b}$ & 0.18 \\
\hline 27 & RE & 0.7 & $0.3^{\mathrm{a}, \mathrm{b}}$ & $0.18^{\mathrm{a}}$ & $0.3^{b}$ \\
\hline 28 & LE & $0.7^{\mathrm{a}, \mathrm{b}}$ & $0.7^{\mathrm{a}}$ & $0.7^{\mathrm{b}}$ & $0^{a}$ \\
\hline 29 & RE & 0.7 & $0.3^{\mathrm{a}, \mathrm{b}}$ & $0^{\mathrm{a}}$ & $0.3^{b}$ \\
\hline 30 & LE & $0.18^{a, b}$ & 0.7 & $0.18^{\mathrm{b}}$ & $0^{a}$ \\
\hline 31 & RE & 0.4 & $0.12^{\mathrm{a}, \mathrm{b}}$ & $0.12^{\mathrm{a}}$ & $0.12^{\mathrm{a}, \mathrm{b}}$ \\
\hline 32 & LE & $0.18^{\mathrm{a}, \mathrm{b}}$ & I & $0.18^{\mathrm{a}, \mathrm{b}}$ & 0.3 \\
\hline 33 & LE & $0.52^{\mathrm{a}, \mathrm{b}}$ & 0.7 & $0.52^{\mathrm{b}}$ & $0.3^{\mathrm{a}}$ \\
\hline
\end{tabular}

Notes: aBetter-seeing eye. bDominant eye. 'Patient 4 suffered from corneal edema on follow-up examination and so visual acuity did not improve. She was lost to follow-up

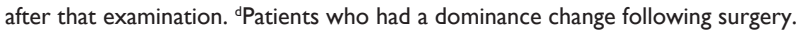

Abbreviations: RE, right eye; LE, left eye; BE, both eyes; BCVA, best-corrected visual acuity; LogMAR, logarithm of the minimum angle of resolution.

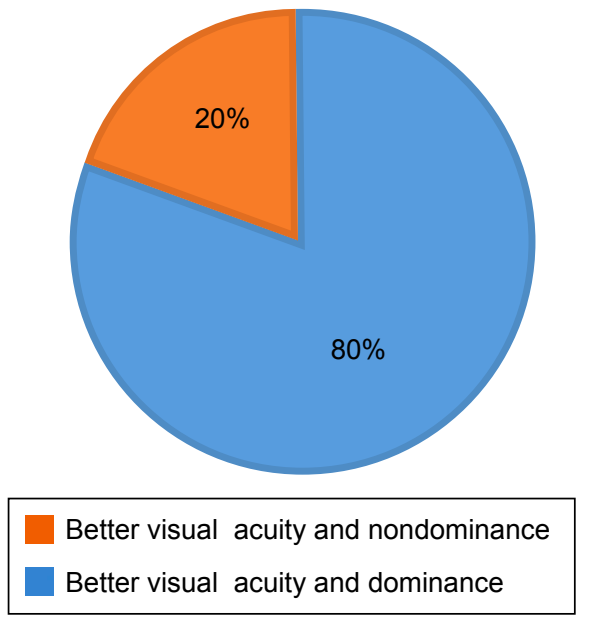

Figure I Correlation between VA and dominance at baseline.

Notes: Of the 25 eyes with better VA in comparison with the fellow eye, $20(80 \%)$ were also dominant.

Abbreviation: VA, visual acuity.
Following surgery, visual acuity in 29 of 33 eyes improved beyond the visual acuity of the fellow eye, making them the better-seeing eye. Of those, seven eyes had a change in dominance ( $P=0.555)$ (Figure 2). There was no change in dominance in eyes that did not become the better-seeing eye following surgery.

As stated earlier, two patients underwent cataract surgery for their fellow eye before reexamination of eye dominance. In the first patient, the left eye (LE) had better visual acuity at baseline (0.52 LogMAR [logarithm of the minimum angle of resolution] LE; 1.3 LogMAR RE) and was also dominant. Following surgery, visual acuity was 0 LogMAR in both eyes, and the RE was found to be dominant. In the second patient, the LE had better visual acuity at baseline ( 0.4 LogMAR LE, 0.7 LogMAR RE) with RE dominance. Following surgery, both eyes had visual acuity of $0.3 \operatorname{LogMAR}$ with RE dominance. 


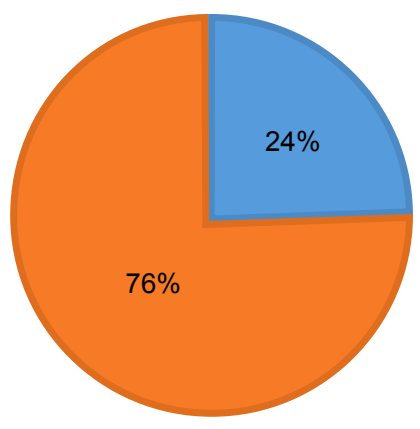

Better visual acuity postsurgery and dominance change Better visual acuity postsurgery and no dominance change

Figure 2 Correlation between VA change following surgery and dominance change.

Notes: Of the 29 eyes in which VA was improved beyond the VA of the fellow eye, seven (24\%) became the dominant eye after being nondominant prior to surgery. Abbreviation: VA, visual acuity.

There was a trend for younger age among patients who had a dominance change (mean age, 64.4 vs 72.1 years in patients with no dominance change; $P=0.054$ ).

\section{Discussion}

Ocular dominance has considerable implications in the field of ophthalmic surgery. The latest Preferred Practice Patterns guidelines published by the American Academy of Ophthalmology consider dominance in the context of monovision correction, both in cataract surgeries ${ }^{6}$ and in keratorefractive surgeries, ${ }^{7}$ stating that the dominant eye is usually corrected for distance.

To our knowledge, this is the first study reported in the literature to assess whether ocular dominance as tested by a sighting dominance technique is a constant characteristic following cataract surgery.

Indeed, in our study, $21.2 \%$ of eyes had a change in dominance following cataract surgery, showing that dominance is in fact a plastic attribute.

The relationship between visual acuity and ocular dominance was examined in the past. Rosenbach was the first author to discuss ocular dominance as early as 1903 , claiming that the dominant eye is not always the eye with better visual acuity. ${ }^{8}$ A recent article reviewing previous published studies showed that no correlation between the two was ever proven. ${ }^{9}$ Our study shows a correlation between visual acuity and eye dominance, as most eyes that had better visual acuity than fellow eyes also were dominant. That strong correlation was not seen after surgery. We did, however, find that among eyes that had changed dominance, all became the eye with better visual acuity, yet this was not statistically significant. This may be explained by the small sample in our study.
We found a trend between age and dominance change, where younger patients were more likely to have a change in dominance $(P=0.054)$. This finding suggests a possible plasticity in eye dominance that is diminished with age.

We did not find a correlation between handedness and eye dominance $(P=1.0)$. Several studies showed a positive correlation between preferred hand and eye $\mathrm{e}^{10,11}$ while others found no such relationship. ${ }^{12,13}$

Our study has several limitations. First, the sample size is relatively small and so could not find a strong correlation between visual acuity change and dominance change, if indeed such a correlation exists. Second, eye dominance was reexamined a month following surgery. It is possible that dominance change may occur later than a month after cataract surgeries. It is also possible that the effect on dominance is temporary, returning to the previous dominance status after a month time frame. Last, two of the subjects in our study had undergone a surgery in their fellow eyes before being reexamined for dominance.

\section{Conclusion}

In summary, our study shows that eye dominance as tested by a sighting dominance technique is a plastic characteristic, rather than a constant one, and that its plasticity may be age dependent. Therefore, surgical decisions based on sighting dominance techniques to test for the dominant eye may not be needed. Further studies may be required to explain the reasons for dominance change (ie, visual acuity change) and to find whether such a change may occur later than 1 month following surgery as well as ascertain a possible correlation between dominance change and age.

\section{Disclosure}

The authors report no conflicts of interest in this work.

\section{References}

1. Porac C, Coren S. The dominant eye. Psychol Bull. 1976;83(5):880-897.

2. Reiss MR. Ocular dominance: some family data. Laterality. 1997; 2:7-16.

3. Jain S, Arora I, Azar DT. Success of monovision in presbyopes: review of the literature and potential applications to refractive surgery. Surv Ophthalmol. 1996;40(6):491-499.

4. Seijas O, Gomez de Liano P, Gomez de Liano R, Roberts CJ, Piedrahita E, Diaz E. Ocular dominance diagnosis and its influence in monovision. Am J Ophthalmol. 2007;144(2):209-216.

5. WH F. The dominant eye: its clinical significance. Arch Ophthalmol. 1938;4:555-582.

6. AAO Refractive Management/Intervention PPP Panel, Hoskins Center for Quality Eye Care. Cataract in the Adult Eye Preferred Practice Patterns - 2011. AAO Cataract and Anterior Segment PPP Panel, Hoskins Center for Quality Eye Care; 2011.

7. AAO Refractive Management/Intervention PPP Panel, Hoskins Center for Quality Eye Care. Refractive Errors \& Refractive Surgery Preferred Practice Patterns - 2013. AAO Refractive Management/Intervention PPP Panel, Hoskins Center for Quality Eye Care; 2013. 
8. Rosenbach O. Ueber monokulare Vorherrschaft beim binokularen Sehen. [About monocular dominance in binocular vision.] Munchener Medizinische Wochenscrift. 1903;30:1290-1292. German.

9. Pointer JS. The absence of lateral congruency between sighting dominance and the eye with better visual acuity. Ophthalmic Physiol Opt. 2007;27(1):106-110.

10. Eyre MB, Schmeeckle MM. A study of handedness, eyedness and footedness. Child Dev. 1933;4:73-78.
11. Updegraff R. Ocular dominance in young children. $J$ Exp Psychol. 1932;15(6):758-766.

12. Groden G. Lateral preference in normal children. Percept Mot Skills. 1969;28:213-214.

13. Geldard FA, Crockett WB. The binocular acuity relation as a function of age. J Genet Psychol. 1930;37:139-145.
Clinical Ophthalmology

\section{Publish your work in this journal}

Clinical Ophthalmology is an international, peer-reviewed journal covering all subspecialties within ophthalmology. Key topics include: Optometry; Visual science; Pharmacology and drug therapy in eye diseases; Basic Sciences; Primary and Secondary eye care; Patient Safety and Quality of Care Improvements. This journal is indexed on

Submit your manuscript here: http://www.dovepress.com/clinical-ophthalmology-journal

\section{Dovepress}

PubMed Central and CAS, and is the official journal of The Society of Clinical Ophthalmology (SCO). The manuscript management system is completely online and includes a very quick and fair peer-review system, which is all easy to use. Visit http://www.dovepress.com/ testimonials.php to read real quotes from published authors. 